\title{
Editorial
}

\section{There Is More than One Way to Catch a Bug}

\author{
Claudia Tueller \\ Department of Pulmonology, University Hospital Bern, Bern, Switzerland
}

Tuberculosis (TB) kills. In 2007 there were an estimated 9.27 million new TB cases worldwide and about 1.78 million people died from the disease in the same year. Sputum smear microscopy remains the primary tool for TB diagnosis in most countries, but only an estimated $44 \%$ of TB cases are smear positive [1]. Though culture of TB bacteria is more sensitive, it may take several weeks to diagnosis due to low growth rates. Research is ongoing to develop the best diagnostic strategy for smear-negative cases (still 5.2 million people after all), with 'best' in this context implying highly sensitive, specific, fast, reliable and, last but not least, cost effective.

Recently published papers on the diagnosis of smearnegative pulmonary TB focus on the improvement in clinical judgment, specimen collection or specimen processing, and innovative laboratory technologies. A score based on demographic data, symptoms, past medical history and chest X-ray findings for rapid identification of patients with pulmonary TB reached a sensitivity of $93 \%$, but had a very low specificity (42\%) questioning its clinical significance [2]. New technologies such as LED fluorescence microscopy and bleach microscopy might improve sensitivity of smear microscopy [3]. In developed countries, flexible bronchoscopy in patients unable to produce sputum or with smear-negative sputum might accelerate the diagnostic procedure, especially when TBspecific nucleic acid amplification techniques or enzymelinked immunospot assays are performed on bronchoal- veolar lavage fluid or mononuclear cells $[4,5]$. Single serologic antibody detection tests for TB lack sensitivity, but might be promising when used as multiple-antigen tests in combination with other procedures [6]. There are many other diagnostic tools under investigation, such as volatile organic compounds, gold nanoparticle probes, biomarkers in QuantiFERON supernatants for example. However, none of the above-mentioned strategies reaches sufficient diagnostic yield to replace sputum smear microscopy and TB culture.

In this issue of Respiration, Lee et al. [7] propose another approach for the rapid diagnosis of sputum smearnegative pulmonary TB. In their retrospective analysis of 84 patients with confirmed active pulmonary $\mathrm{TB}$ and with a negative sputum smear, they compared the diagnostic value of clinical findings, chest high-resolution (HR) CT, sputum TB-PCR and the IFN- $\gamma$ release assay (IGRA) for the diagnosis of active pulmonary TB. As has been shown previously, they found none of these parameters alone to be of sufficient diagnostic value. However, they describe a high positive and negative predictive value for the combined utilization of IGRA and chest HRCT. A congruent result of HR-CT and IGRA, i.e. HR-CT findings suggestive of pulmonary $\mathrm{TB}$ and a positive IGRA, predicted the correct diagnosis in 23 of 24 patients (positive predictive value 96\%). The negative predictive value of congruent negative HR-CT findings and IGRA was $92 \%$ : in 23 of 25 patients pulmonary TB was correct-

\section{KARGER}

Fax +4161306 1234

E-Mail karger@karger.ch

www.karger.com (c) 2010 S. Karger AG, Basel

0025-7931/10/0796-0450\$26.00/0

Accessible online at:

www.karger.com/res
Dr. Claudia Tueller

Department of Pulmonology

University Hospital Bern

CH-3010 Bern (Switzerland)

Tel. +41 31632 2111, Fax +41 31632 1404, E-Mail claudia.tueller@insel.ch 
ly excluded. Despite some limitations of the study (retrospective analysis, some variables missing and small sample size), the HR-CT-IGRA combination is a promising approach that might assist clinicians in their decision to start TB therapy or isolate hospitalized patients when sputum smear is negative.

It must be kept in mind that the results of this study are of little value for the countries with the highest burden of TB. HR-CT and IGRA are expensive, require expertise and are unavailable in developing countries. Furthermore, HIV co-infection is frequent in these coun- tries, and this study was performed in HIV-negative patients. In the appropriate setting, i.e. intermediate- to low-burden countries with sufficient health care resources to perform HR-CT and IGRA in patients with suspected pulmonary $\mathrm{TB}$ and negative sputum smear, the combined use of HR-CT and IGRA might substantially improve decision making, and obviate the need for further diagnostic procedures in cases with congruent results. We are now waiting for prospective evaluation of this approach.

\section{References}

1 World Health Organization: Global Tuberculosis Control 2009 - Epidemiology, Strategy, Financing. Geneva, WHO, 2009.

-2 Solari L, Acuna-Villaorduno C, Soto A, Agapito J, Perez F, Samalvides F, Zegarra J, Diaz J, Gotuzzo E, Van der Stuyft P: A clinical prediction rule for pulmonary tuberculosis in emergency departments. Int J Tuberc Lung Dis 2008;12:619-624.

3 World Health Organization: New Laboratory Diagnostic Tools for Tuberculosis Control. Geneva, WHO, 2008.
-4 Tueller C, Chhajed PN, Buitrago-Tellez C, Frei R, Frey M, Tamm M: Value of smear and PCR in bronchoalveolar lavage fluid in culture positive pulmonary tuberculosis. Eur Respir J 2005;26:767-772.

5 Jafari C, Thijsen S, Sotgiu G, Goletti D, Dominguez Benitez JA, Losi M, Eberhardt R, Kirsten D, Kalsdorf B, Bossink A, Latorre I, Migliori GB, Strassburg A, Winteroll S, Greinert U, Richeldi L, Ernst M, Lange C, Tuberculosis Network European Trialsgroup: Bronchoalveolar lavage enzymelinked immunospot for a rapid diagnosis of tuberculosis: a Tuberculosis Network European Trialsgroup study. Am J Respir Crit Care Med 2009;180:666-673.
6 Steingart KR, Dendukuri N, Henry M, Schiller I, Nahid P, Hopewell PC, Ramsay A, Pai $M$, Laal S: Performance of purified antigens for serodiagnosis of pulmonary tuberculosis: a meta-analysis. Clin Vaccine Immunol 2009;16:260-276.

7 Lee H-M, Shin JW, Kim JY, Park IW, Choi BW, Choi JC, Seo JS, Kim CW: HRCT and whole-blood interferon- $\gamma$ assay for the rapid diagnosis of smear-negative pulmonary tuberculosis. Respiration 2010;79:454-460. 